\title{
How Do Consumers Differentiate between Fresh Food Stores
}

\author{
P.J. Batt \\ Curtin University \\ Perth \\ Australia
}

Key words: store choice, consumer behaviour, cross shopping

\begin{abstract}
In making their decision to purchase fresh food from a retail store, the consumer behaviour literature identifies three key factors: (i) offer quality; (ii) a competitive price; and (iii) convenience. In an effort to reduce the decline in patronage as more fresh produce moves directly from growers to the major chain stores, the Perth Metropolitan Market commissioned an exploratory study to identify how consumers choose between alternative retail stores. Four categories of store were identified: (i) the major supermarkets; (ii) independent supermarkets; (iii) green grocers; and (iv) grower direct markets. Results reveal that for the major supermarkets, all three factors: quality, competitive price and convenience were rated equally, implying a one-stop shop. For the independent supermarkets, which are primarily located closer to the consumers' place of residence, convenience was the key determining variable. For the independent green grocers and grower direct markets, superior quality and a wide range of product was most important. While consumers generally purchase $80 \%$ of the fresh produce they consumed from their preferred place of purchase, convenience was identified as the main reason to purchase from another retail store.
\end{abstract}

\section{INTRODUCTION}

There is significant empirical and anecdotal evidence to demonstrate that as competition between the major supermarket chains intensify, greater quantities of fresh produce are purchased from growers direct, by-passing the traditional wholesale markets (Batt 2006). Improved quality, a more consistent and reliable supply, a guaranteed price and lower cost are the main reasons believed to explain the shift towards more direct sales (Hughes and Merton 1996). However, as food integrity issues become more important, the ability to trace product back to source has become a critical determinant in the retailers' choice of preferred suppliers (Wilson 1996; Fearne and Hughes 1999).

At the consumer level, household buyers consistently report that the two most dominant factors that impact upon their decision to purchase fresh produce in a retail store is quality and a competitive price (Batt 2004). Quality however is a multi-faceted variable that considers not only the extrinsic quality attributes (freshness, colour, size and shape), but also the intrinsic quality attributes (taste, flavour, texture and mouth feel), the credence attributes (method of production, fair trade and sustainable production) and the service quality attributes that are associated with the shopping experience itself (customer advice, ambience, convenience, credit facilities, etc.)(Batt 2007).

There is ample empirical evidence to demonstrate that as personal disposable income increases, the service quality dimensions become increasingly more important in the consumers' decision to purchase (Shepherd 2005). With more women in the work force, convenience is emerging as a key decision variable (Fearne 1992; Martech 2005). 
Convenience includes such things as the hours of operation, product range, the capacity to interact with the product, sample the product and perform concurrently a multiple number of other transactions (Geuens et al. 2003). In general, the household buyers' preference for "one-stop" shopping has greatly encouraged the expansion of the supermarket format.

However, it is also abundantly clear that as the supermarkets seek to control costs by reducing the number of competing lines and product variants on the shelf, they have alienated a large segment of the market. A low price is not important to all household buyers and a growing segment of the market is demonstrating that it is not only prepared to pay more for the desired intrinsic and credence quality attributes, but also for the associated value-added services.

Although food shopping is often regarded as a low involvement purchase decision (Beharrell and Denison 1995), there is increasing evidence that food and grocery buyers often patronise multiple stores (Prasad and Aryasri 2011). Koistinen and Jarvinen (2009) report that almost $80 \%$ of consumers shopped at five or more retail stores in a three month period and $25 \%$ purchased from at least ten retailers. Consumers engage in crossshopping because they have alternatives, but they may also turn to other retail formats where they are unable to fulfil their needs, or to take advantage of promotional offers.

This exploratory study sought to identify the criteria that most influenced the household buyers' choice of retail store when purchasing fresh produce and to investigate the reasons for multiple store patronage.

\section{METHODOLOGY}

For this study, under-graduate students in their third and final year of the Bachelor of Agribusiness program at Curtin University undertook random intercept surveys of household buyers in the Perth metropolitan area. Respondents were interviewed at suburban shopping centres and independent IGA stores because most shopping malls do not allow surveys to be conducted on the premises and the two major retailers (Coles and Woolworths) do not allow interviews to be conducted in-store.

Each student was required to undertake no less than 40 surveys. With a class size of 12 , the target sample size was 480 , which for a city the size of Perth was considered to be the minimum number necessary to have any real confidence in the results.

Surveys were conducted over a two week period in April 2008, across the week and at a range of different times to ensure that the sample selected was representative of the population. A number of demographic questions were asked of the respondents to enable a comparison to be made with the ABS census.

At the commencement of the interview, two qualifying questions were asked: (1) Are you the person in your household who ordinarily makes the decision to buy fresh produce? This eliminated those respondents who could not truthfully answer the questions; and (2) Do you have 15 minutes available to complete this questionnaire? This eliminated those respondents who did not have the time and were more likely to fail to adequately complete the questionnaire.

The questionnaire explored such issues as: (i) the frequency of purchase; (ii) the place of purchase; (iii) what proportion of their purchases respondents made from this store; (iv) why respondents chose to purchase from this retail store; and (v) why the respondents purchased from other retail outlets. The survey concluded with a number of demographic variables including gender, age, country of birth, place of residence, 
occupation and household income. Responses were encoded and entered into the Statistical Package for Social Sciences (SPSS) for analysis.

\section{RESULTS}

The majority of consumers in Perth purchased fresh fruit and vegetables only one time per week $(52 \%)$ (Table 1$)$.

The two major supermarket chains accounted for some $44 \%$ of sales, with the independent supermarkets accounting for $26 \%$ of sales and green grocers accounting for $21 \%$ (Table 2). Grower direct markets accounted for less than $9 \%$ of sales.

Irrespective of the place of purchase, most consumers purchased $80 \%$ of their fresh fruit and vegetables from their preferred retail outlet (Table 3 ).

When respondents were asked what they most liked about their preferred retail store for purchasing fresh fruit and vegetables, the three most frequently cited responses were fresh produce (32\%), a competitive price (30\%) and good quality produce (29\%) (Table 4). For some $22 \%$ of respondents, convenience was an important consideration. A further $18 \%$ of respondents cited proximity to home (18\%) and a wide range of other food products $(15 \%)$. The two other most frequently cited variables included the wide range of fresh fruit and vegetables available (16\%) and good customer service (12\%).

For those respondents who purchased the majority of the fresh fruit and vegetables they consumed from supermarkets, the things they most liked about their preferred retail store was the competitive price (31\%), the freshness of the produce $(29 \%)$, the convenience $(28 \%)$, the good quality (23\%), the wide range of other food $(20 \%)$, the proximity to home $(20 \%)$ and the wide range of fresh produce $(17 \%)$.

However, for those respondents who purchased the majority of their fresh fruit and vegetables from independent supermarkets, the most frequently cited variables were good quality $(27 \%)$, freshness of the produce $(25 \%)$, convenience $(24 \%)$, proximity to home $(22 \%)$, friendly staff $(18 \%)$, a competitive price $(17 \%)$ and wide range of produce $(14 \%)$. This would suggest that those respondents who purchased the majority of their fresh fruit and vegetables from independent supermarkets valued good quality and convenience more highly. Given that competitive price was cited less frequently and with the addition of a customer service variable (friendly staff), these respondents seem more willing to pay for superior quality, convenience and superior customer service.

For those respondents who purchased the majority of fresh fruit and vegetables from green grocers, the three most frequently cited variables were fresh produce (43\%), good quality $(41 \%)$ and a competitive price (40\%). For these more discerning respondents, good quality and competitive price were combined to collectively provide superior value. However, while this clearly signalled a greater propensity to pay for superior quality, the emphasis on price suggested that this value judgement was made relative to the prices charged presumably by the supermarkets, which the respondents probably frequented to purchase other household goods. While green grocers were also perceived to offer a wider range of fresh produce (20\%) and to have friendly staff (20\%), convenience $(12 \%)$ and proximity to the home (13\%) were cited significantly less often, which implied that respondents were prepared to go out of their way to purchase superior quality fresh fruit and vegetables. There was also some evidence to suggest that for some $11 \%$ of respondents, their decision to purchase fresh fruit and vegetables from small independent retailers was in part a protest against the concentration in the retail sector.

The situation was not too dissimilar for those respondents who chose to purchase the majority of their fresh fruit and vegetables from grower direct outlets. The most 
frequently cited responses here included fresh produce (42\%), good quality produce (42\%), a competitive price (32\%) and a wide range of other food $(26 \%)$. This suggested that in visiting grower direct markets, the respondents were not only prepared to travel some distance from the home, but also to engage in a larger food shop, perhaps purchasing their bread, fish, meat and other gourmet food products. For some $10 \%$ of the respondents, purchasing from grower direct markets was perceived to be a way of supporting local producers.

The most frequently cited reason for purchasing fresh fruit and vegetables from another retail store was convenience $(35 \%)$ (Table 5). This would suggest that the respondent needed a particular product that was not available from their preferred store, perhaps they had forgotten to buy it, or they had consumed some or all of the produce that they had purchased prematurely.

For some $24 \%$ of respondents, the main reason they gave for changing retail stores was a more competitive price. Although the purchasing of fresh fruit and vegetables is generally regarded as being a low involvement decision, it appears that some respondents, especially those on low incomes, often switched stores to take advantage of short-term price inducements, initiated perhaps by sales promotions and advertising, or they simply happened to be in-store at the time or passing the store. Happenstance was reported as the being the main reason for purchasing from another retail store for some $20 \%$ of respondents. In this situation, purchases were most likely made on impulse: the consumer saw the product, it looked appealing, it was competitively priced, or the respondent simply felt that they wanted to eat the product or to use the product in the preparation of a meal.

Nevertheless, for some $10 \%$ of respondents, the poor quality of the produce offered for sale and the lack of fresh produce provided a sufficient inducement to purchase elsewhere. While one poor experience was unlikely to cause respondents to change stores, a number of adverse occurrences in quick succession, or the accumulation of a number of adverse experiences over time, may eventually persuade the respondent to explore alternative options. Given however the value that most respondents placed on convenience, a conscious decision to change stores will only be made after weighing up the perceived price, the quality of the produce, the range of fresh food offered and the level of customer service, relative to the alternatives. Hence any decision to change stores is likely to take some time or to be occasioned by some major external event.

\section{CONCLUSION}

To varying degrees, each of the retail store formats offered something different to fresh fruit and vegetable buyers. For the major supermarket chains, the one-time per week, one-stop shop was the key attraction. Quality, a competitive price and convenience were each cited a similar number of times. For the small independent supermarkets, proximity to the home, more convenient trading hours and friendly staff were the key points of difference. In this instance, convenience was a much greater consideration than a competitive price. For both the green grocers and grower direct markets, superior quality was the key variable that differentiated them from the supermarkets. In both instances, convenience and proximity to the home were cited much less often, indicating that respondents were prepared to go out of their way to purchase what they wanted. For the green grocers, a wider range of fresh produce, more friendly and knowledgeable staff were the key points of difference. However, the challenge was to offer superior quality and service at a competitive price, suggesting that most consumers made some conscious 
comparison of the quality and prices offered by the supermarkets. A point of differentiation however, was the desire by many consumers to support local retailers.

For the grower direct markets, the key point of differentiation was the wide range of other fresh food products, suggesting that some consumers went out of their way to purchase better quality fresh fruit and vegetables, fish and meat, freshly baked bread and other gourmet food products. For these consumers price was not so important, with many believing that they were supporting local producers.

\section{Literature Cited}

Batt, P.J. 2004. Consumer sovereignty: exploring consumer needs in Johnson, G.I and Hofman, P.J. (ed), Agriproduct Supply-Chain Management in Developing Countries. Proceedings of a workshop held in Bali, Indonesia 19-22 August 2003. ACIAR Proceedings No. 119. 77-87.

Batt, P.J. 2006. Fulfilling customer needs in agribusiness supply chains in Batt, P.J. (ed), Proceedings of the First International Symposium on Improving the Performance of Supply Chains in the Transitional Economies. Acta Horticulturae 699. 83-90.

Batt, P.J. 2007. Expanding the quality concept: an holistic approach in Batt, P.J. and Cadilhon (ed), Proceedings of an International symposium on fresh produce supply chain management. Dec 6-10, Lotus Pang Suan Kaew hotel, Chiang Mai, Thailand. RAP Publication 2007/21. FAO. Bangkok. 281-290.

Beharrell, B. and Denison, T.J. 1995. Involvement in a routine food shopping context. British Food Journal 93(7):24-29.

Fearne, A. 1992. The Great British Potato: A Study of Consumer Demand, Attitudes, and Perceptions. British Food Journal. 94(6): 22-29.

Fearne, A. and Hughes, D. 1999. Success factors in the fresh produce supply chain: insights from the UK. Supply Chain Mngt. 4(3): 120-128.

Geuens, M., Brengman, M. and Jegers, R. 2003. Food retailing now and in the future: a consumer perspective. J Retailing and Consumer Services 10(4):241-251.

Hughes, D and Merton, I. 1996. Partnership in produce: the J. Sainsbury approach to managing the fresh produce supply chain. Supply Chain Mngt. 1(2): 4-6.

Koistinen, K. and Jarvinen, R. 2011. Consumer observations on channel choices competitive strategies in Finnish grocery retailing. $\mathrm{J}$ of Retailing and Consumer Services 16(4): 260-270.

Martech Consulting. 2005. Trends that impact New Zealand's horticultural food exports. Growing futures case study series. (available at www.martech.co.nz)

Prasad, C.J. and Aryasri, A.R. 2011. Effect of shopper attributes on retail format choice behaviour for food and grocery retailing in India. Intl $\mathrm{J}$ of Retail and Distribution Management 39(1): 68-86.

Shepherd, A.W. 2005. The implications of supermarket development for horticultural farmers and traditional marketing systems in Asia. In FAO/AFMA/FAMA Regional Workshop on the Growth of Supermarkets as Retailers of Fresh Produce. Kuala Lumpur.

Wilson, N. 1996. Supply chain management: a case study of a dedicated supply chain for bananas in the UK grocery market. Supply Chain Mngt. 1(2): 28-35. 
Table 1: Frequency of purchasing fresh fruit and vegetables

\begin{tabular}{|l|c|c|}
\hline & $\mathrm{N}$ & $\%$ \\
\hline Daily & 13 & 2.7 \\
\hline 2-3 times per week & 168 & 35.5 \\
\hline One time per week & 247 & 52.2 \\
\hline One time every two weeks & 45 & 9.5 \\
\hline & & \\
\hline & 473 & 100.0 \\
\hline
\end{tabular}

Table 2: Preferred place of purchase

\begin{tabular}{|l|c|c|}
\hline & $\mathrm{N}$ & $\%$ \\
\hline Coles/Woolworths & 209 & 44.2 \\
\hline Independent supermarkets & 122 & 25.8 \\
\hline Green grocers & 100 & 21.1 \\
\hline Grower direct markets & 42 & 8.9 \\
\hline & & \\
\hline & 473 & 100.0 \\
\hline
\end{tabular}

Table 3: Mean percent of product purchased by preferred place of purchase

\begin{tabular}{|l|c|c|}
\hline & Mean & SD \\
\hline Coles/Woolworths & 79.06 & 17.94 \\
\hline Independent supermarkets & 83.04 & 15.71 \\
\hline Green grocers & 82.37 & 15.70 \\
\hline Grower direct markets & 79.33 & 16.67 \\
\hline & & \\
\hline & 80.96 & 17.05 \\
\hline
\end{tabular}


Table 4: What respondents most like about their preferred retail store

\begin{tabular}{|l|c|c|c|c|c|}
\hline \multirow{2}{*}{} & \multicolumn{5}{|c|}{ Percent citations } \\
\cline { 2 - 6 } & ALL & SM & ISM & GG & GDM \\
\hline Fresh produce & $\mathbf{3 2 . 3}$ & 29.3 & 24.8 & 43.1 & 41.9 \\
\hline Competitive price & $\mathbf{2 9 . 9}$ & 31.3 & 17.4 & 40.0 & 32.3 \\
\hline Good quality & $\mathbf{2 9 . 0}$ & 22.7 & 27.3 & 41.1 & 41.9 \\
\hline Convenient & $\mathbf{2 2 . 1}$ & 28.3 & 24.0 & 11.6 & 12.9 \\
\hline Close to home & $\mathbf{1 8 . 3}$ & 19.7 & 22.3 & 12.6 & 12.9 \\
\hline Good selection/wide range & $\mathbf{1 6 . 2}$ & 17.2 & 14.0 & 20.0 & 3.2 \\
\hline Wide range of other food & $\mathbf{1 5 . 1}$ & 20.2 & 8.3 & 10.5 & 25.8 \\
\hline Friendly staff & $\mathbf{1 1 . 8}$ & 4.5 & 18.2 & 21.1 & 9.7 \\
\hline Good presentation & $\mathbf{5 . 5}$ & 4.5 & 7.4 & 6.3 & \\
\hline Easy to access & $\mathbf{5 . 0}$ & 6.6 & 4.1 & 5.3 & \\
\hline Product availability & $\mathbf{4 . 8}$ & 7.1 & 5.8 & & \\
\hline Privately owned & $\mathbf{4 . 8}$ & & 5.0 & 10.5 & 6.4 \\
\hline Support local growers & $\mathbf{4 . 1}$ & 1.5 & 3.3 & 6.3 & 9.7 \\
\hline Value for money & $\mathbf{4 . 0}$ & 2.5 & 2.5 & 8.4 & 6.4 \\
\hline Clean product & $\mathbf{3 . 7}$ & 4.0 & 2.5 & 6.3 & \\
\hline Open when I need them & $\mathbf{3 . 3}$ & 1.5 & 7.4 & 2.1 & 3.2 \\
\hline Parking & $\mathbf{2 . 6}$ & 3.3 & & 5.3 & 3.2 \\
\hline Fast/spacious check out & $\mathbf{2 . 6}$ & 2.0 & 3.3 & 1.1 & 6.4 \\
\hline One-stop-shop & $\mathbf{1 . 7}$ & 3.5 & & 1.1 & 3.2 \\
\hline Trolleys and baskets & $\mathbf{1 . 5}$ & 1.0 & 0.8 & 1.1 & 6.4 \\
\hline Product knowledge & $\mathbf{1 . 3}$ & & 3.3 & 3.1 & \\
\hline Good signage & $\mathbf{1 . 3}$ & 2.5 & 0.8 & & \\
\hline Organic produce & $\mathbf{1 . 1}$ & 1.0 & 1.7 & 1.1 & \\
\hline Credit facilities & $\mathbf{1 . 1}$ & & 4.1 & & \\
\hline Offer price specials/discounts & $\mathbf{1 . 1}$ & 1.5 & & & \\
\hline Self select produce & $\mathbf{0 . 9}$ & 1.5 & & 1.1 & \\
\hline Accept phone orders & $\mathbf{0 . 7}$ & & 2.5 & & \\
\hline Replace poor quality product & $\mathbf{0 . 7}$ & & 0.8 & 2.1 & \\
\hline More healthy produce & $\mathbf{0 . 7}$ & 1.0 & & 1.1 & \\
\hline Get product not on shelf & $\mathbf{0 . 4}$ & 0.5 & 0.8 & & \\
\hline Have boxes to carry produce & $\mathbf{0 . 4}$ & & & 1.1 & 3.2 \\
\hline & & & & & \\
\hline N & $\mathbf{4 5 8}$ & 198 & 121 & 95 & 31 \\
\hline
\end{tabular}

where $\mathrm{SM}=$ supermarket

ISM = independent supermarket

$\mathrm{GG}=$ green grocer

GDM = grower direct market 
Table 5: Why respondents purchase fresh produce from other retail outlets

\begin{tabular}{|c|c|c|c|c|c|c|c|}
\hline & \multicolumn{5}{|c|}{ Citations } & \multirow[t]{2}{*}{$\mathrm{N}$} & \multirow[t]{2}{*}{$\%$} \\
\hline & 1 & 2 & 3 & 4 & 5 & & \\
\hline More convenient & 108 & 14 & 5 & 1 & & 160 & 35.4 \\
\hline Offer better price & 51 & 37 & 12 & 9 & 1 & 110 & 24.3 \\
\hline Happenstance & 60 & 23 & 5 & 1 & & 89 & 19.7 \\
\hline Have a wider range & 41 & 29 & 10 & 2 & & 82 & 18.1 \\
\hline More fresh & 19 & 21 & 7 & 1 & & 48 & 10.6 \\
\hline Better quality & 27 & 14 & 4 & 1 & & 46 & 10.2 \\
\hline Closer to home & 19 & 18 & 5 & 2 & 1 & 45 & 10.0 \\
\hline Open for longer & 18 & 11 & 2 & & & 31 & 6.9 \\
\hline Don't purchase elsewhere & 27 & & & & & 27 & 6.0 \\
\hline Support local growers & 13 & 2 & 2 & 2 & 1 & 20 & 4.4 \\
\hline Time for a change & 7 & 9 & 2 & & & 18 & 4.0 \\
\hline Out of stock & 12 & 2 & 3 & & & 17 & 3.8 \\
\hline Ran out & 11 & 4 & 1 & & & 16 & 3.5 \\
\hline Easier to access & 7 & 5 & 1 & & & 13 & 2.9 \\
\hline Impulse & 6 & 2 & 1 & 1 & 1 & 11 & 2.4 \\
\hline Special requirement/need & 4 & 4 & 2 & 1 & & 11 & 2.4 \\
\hline Better service & 1 & 3 & 5 & & & 9 & 2.0 \\
\hline Only needed a small amount & 4 & 2 & 1 & 1 & & 8 & 1.8 \\
\hline Friends recommended & & 1 & 6 & & & 7 & 1.5 \\
\hline Favourite store closed & 2 & 2 & 2 & & & 6 & 1.3 \\
\hline Open on Sunday & 2 & 1 & 1 & & & 5 & 1.1 \\
\hline Promote seasonal fruit & 3 & 1 & & & 1 & 5 & 1.1 \\
\hline Forgotten something & 2 & 2 & 1 & & & 5 & 1.1 \\
\hline Have organic produce & 1 & 1 & 1 & 1 & & 4 & 0.9 \\
\hline Meet friends & 1 & 1 & & 1 & & 3 & 0.7 \\
\hline Support small business & 2 & 1 & & & & 3 & 0.7 \\
\hline Close to another shop & 2 & 1 & & & & 3 & 0.7 \\
\hline Bad experience with others & 2 & & & & & 2 & 0.4 \\
\hline $\mathrm{N}=452$ & & & & & & & \\
\hline
\end{tabular}

